\title{
Quando o abrigado recusa a adoção: a partir da análise do filme "De repente uma
}

\section{família"}

\author{
When the sheltered refuses adoption: from the analysis of the movie "Instant Family" \\ Cuando el resguardado rechaza la adopción: del análisis de la película "Familia al instante"
}

Recebido: 16/11/2021 | Revisado: 25/11/2021 | Aceito: 28/11/2021 | Publicado: 10/12/2021

\author{
Letícia Alves Pinheiro \\ ORCID: https://orcid.org/0000-0003-1512-6450 \\ Faculdade de Ensino do Piauí, Brasil \\ Email: leticiapsi2022@gmail.com \\ Sara Castro de Souza \\ ORCID: https://orcid.org/0000-0002-6116-5365 \\ Faculdade de Ensino do Piauí, Brasil \\ Email: saracastropsi@hotmail.com \\ Sara Cavalcanti Souza \\ ORCID: https://orcid.org/0000-0003-3795-7431 \\ Centro de Ensino Unificado do Piauí, Brasil \\ Email: scavalcantis@yahoo.com.br \\ Ruth Raquel Soares de Farias \\ ORCID: https://orcid.org/0000-0002-0988-0900 \\ Faculdade de Ensino do Piauí, Brasil \\ Email: ruthraquelsf@gmail.com
}

\begin{abstract}
Resumo
No filme é retratado a realidade do processo de adoção, os preconceitos existentes, a dificuldade de adotar uma criança/adolescente quando esta possui um apego à família de origem onde geralmente não aceita ser adotada por outra família. O objetivo desse artigo foi analisar as influências da recusa no processo de adoção por parte da criança/adolescente, descrevendo a prática da adoção com crianças e adolescentes que vivem em abrigos por meio do filme "De repente uma família". Na metodologia foi utilizado a abordagem qualitativa, com objetivos descritivos, fazendo uso da análise textual, análise de conteúdo e análise da imagem e do som. Nos resultados utilizou-se de bases cognitivas e comportamentais para identificar as cenas importantes do filme e discorrer com autores sobre as temáticas apresentadas. Concluiu-se que através de uma análise do comportamento dos personagens foi possível perceber que a criança maior leva mais tempo para sentir confiança e se permitir fazer parte da nova família, por achar que não será querida em um ambiente desconhecido com pessoas que ela ainda não entende o que motivou aquela pessoa a querer adota-la.
\end{abstract}

Palavras-chave: Adoção; Terapia cognitivo comportamental; Análise do comportamento.

\begin{abstract}
In the film is portrayed the reality of the adoption process, the existing prejudices, the difficulty of adopting a child/adolescent when he has an attachment to the family of origin and generally does not accept to be adopted by another family. The aim of this article was to analyze the influences of refusal in the adoption process by the child/adolescent, describing the adoption of children and adolescents that were living in orphanages in the movie "Instant Family". The methodology used the qualitative approach, with descriptive objectives, making use of textual analysis, content, image, and sound analysis. For the results, cognitive and behavioral bases were used to identify the important scenes of the film and discuss the themes presented with the authors. It was concluded that through an analysis of the speech and behavior of the characters, it was possible to realize that the older children take longer to feel confident and allow themselves to be part of a new family because the child believes he or she will not be loved in the unknown environment with people who still do not understand the child nor what motivated that person to adopt the child.
\end{abstract}

Keywords: Adoption; Cognitive behavioral therapy; Behavior analysis.

\section{Resumen}

En la película se retrata la realidad del proceso de adopción, los prejuicios existentes, la dificultad de adoptar a un niño/adolescente cuando tiene un apego a la familia de origen y que generalmente no acepta ser adoptado por otra familia. El objetivo de este artículo fue analizar las influencias del rechazo en el proceso de adopción por parte del niño/adolescente, describiendo la práctica de la adopción con niños y adolescentes que viven en albergues a través de 
la película "De repente una familia". La metodología utilizó el enfoque cualitativo, con objetivos descriptivos, haciendo uso del análisis textual, el análisis de contenido y el análisis de imagen y sonido. En los resultados, se utilizaron bases cognitivas y conductuales para identificar las escenas importantes de la película y discutir con los autores sobre los temas presentados. Se concluyó que a través de un análisis del habla y comportamiento de los personajes fue posible darse cuenta de que el niño mayor tarda más en sentirse seguro y dejarse formar parte de la nueva familia, pues piensa que no será amada en un ambiente desconocido con personas que aún no entienden qué motivó a esa persona a querer adoptarla.

Palabras clave: Adopción; Terapia cognitivo conductual; Análisis del comportamiento.

\section{Introdução}

O filme cujo título original é “Instant Family” que traduzido para o português é "De Repente Uma Família" com duração de 1h59min, foi lançado no ano de 2018 e produzido pelo diretor Sean Anders onde retrata a história de um casal que não possui filhos e pretendem adotar uma adolescente que tem dois irmãos menores, no entanto são surpreendidos pelos desafios que encontram na fase de convívio, onde pensam em desistir da adoção por acharem não serem capazes de lidar com os problemas que surgem. O filme foi baseado na experiência do diretor que adotou três crianças e posteriormente ocorreu a desistência por decisão da adolescente pois a mesma tinha esperanças de retornar para sua família biológica e não aceitou ser adotada.

A narrativa do filme retrata bem a realidade de crianças e adolescentes que vivem em abrigos, onde geralmente muitos querem retornar para o convívio da família, porém os parentes muitas vezes não estão aptos para recebe-los, em contrapartida também ocorre de os pretendentes à adoção desistirem no meio do processo por não se sentirem preparados para os desafios.

Conforme a lei 12.010/09 que fala sobre adoção, ao ocorrer o afastamento da criança/adolescente do convívio familiar por motivos diversos, estes são levados para um lar temporário até que a família esteja estruturada e ela possa retornar ao convívio familiar. Quando todas as tentativas de reintegra-lo no seio familiar são falhas, cabe à justiça disponibiliza-los para adoção (Brasil, 2009).

Adotar é a forma de proporcionar um ambiente familiar no qual a criança foi privada e assim possibilitar a ela o sentimento afetivo da figura materna ou paterna (Paiva, 2004). No dicionário, Amora (2009) define que o termo adotar significa aceitar como filho, ou seja, uma pessoa cria e educa uma criança/adolescente como sendo seu filho mesmo que não possua o mesmo gene (Gonçalves, 2012).

Ao mesmo tempo justifica-se por impactos causados pelo despreparo de futuros pais adotivos, quando há ausência de um vínculo afetivo que acaba como consequência causando a devolução de crianças/adolescentes após a adoção. Assim, é possível notar que essa não construção do vínculo na adoção pode impactar o emocional deles que passam por uma nova rejeição (Souza, 2012).

É notório que os pretendentes à adoção que obtiveram o devido preparo e um direcionamento antes da adoção ser concretizada estes chegaram a uma decisão mais assertiva e bem planejada, pois acarretou a uma reflexão acerca da real necessidade e interesse que possuíam em adotar (Goes, 2014).

Na medida que é importante os pais adotivos estarem cientes do histórico da criança/adolescente bem como traumas e dificuldades que carregam, para que saibam lidar no período de convivência onde na maioria dos casos é um momento desafiador (Sampaio, Magalhães \& Féres-Carneiro, 2018).

Diante do exposto, este artigo teve como objetivo analisar as influências da recusa no processo de adoção por parte da criança/adolescente. Realizou uma análise de filme onde observou comportamentos que respondessem a esse questionamento, verificando as motivações que leva alguns pretendentes a desistirem da adoção e relacionou autores que discorressem sobre o assunto fazendo relação com a realidade. 
O interesse pela análise do filme se deu pela identificação ao assistir o referido filme, onde mostra a adoção com prós e contras de maneira realista, sendo um filme que envolve o espectador do começo ao fim contendo drama e humor simultaneamente.

Essa pesquisa irá contribuir no olhar para a criança/adolescente que vive no abrigo a espera por um lar e muitas vezes não consegue se adaptar à atual família com sentimento de não pertencimento quando o vínculo entre eles não é estabelecido, também podendo contribuir para a área da Psicologia, Serviço Social e Direito, que essas áreas reflitam sobre as problemáticas encontradas quando os futuros pais adotivos não estabelecem um vínculo com os jovens adotados, para que assim evitem a desistência ou devolução dos mesmos após a adoção.

\section{Metodologia}

Foi realizado uma análise de filme com abordagem qualitativa, dando destaque à subjetividade e qualidade dos fatos, não levando em consideração elementos numéricos e estatísticos (Goldenberg, 2004). Os objetivos foram descritivos, onde analisou características encontradas no filme, sendo descritos na íntegra sem interferência (Vergara, 2000).

Penafria (2009) estrutura algumas formas de analisar um filme e para esse trabalho foi utilizado três formas de analisar, a primeira foi a análise textual onde se baseou nos personagens principais, descrevendo-os através da tríade cognitiva da TCC (Terapia cognitiva comportamental) "Representações negativas de si mesmo, do mundo pessoal e do futuro" (Knapp \& Beck, 2008 p. 56). A segunda foi a análise de conteúdo onde foi selecionado comportamentos dos personagens que foram marcantes no filme fazendo relação com as contingências comportamentais onde um comportamento pode ser modificado por um evento (Catania, 1999). A terceira foi a análise da imagem e do som que foi observado o impacto que o som e iluminação causam em determinadas cenas, onde foi dividida as cenas de acordo com as emoções dos personagens principais.

Os personagens principais são Lizzie, uma pré-adolescente que tem dois irmãos mais novos que se chamam Juan e Lita, os três se mudam para casa de Ellie e Pete (pais acolhedores) que passam a serem sua família acolhedora até a efetivação da adoção.

\section{Análise e Discussão dos Dados}

\section{Análise textual}

Foi observado através da fala dos personagens quais as impressões que eles têm de si mesmo, do mundo e do futuro, onde foi analisado os personagens Lizzie (pré-adolescente), Ellie (mãe adotiva), Pete (pai adotivo), Juan e Lita (crianças menores).

Lizzie se vê como uma pessoa incapaz de ser amada por alguém, quando fala para os pais acolhedores: "Vocês não me amam, nem me conhecem". Sua visão de mundo é que as pessoas não se importam com ela, na sua fala "Irei para outra família, sei que só sentem pena de mim". Sua visão de futuro é a de falta de esperança nas pessoas pois para ela apenas a mãe biológica poderia lhe proporcionar amor e proteção quando fala para Ellie "Você é só uma moça branca que quer adotar umas crianças órfãs para se sentir bem consigo mesma”.

Ellie se vê como uma mãe imperfeita que não é capaz de educar os filhos adotivos quando fala "Não demorou muito e eles já nos odeiam". Na sua visão de mundo as crianças não reconhecem seus esforços, quando fala "A gente faz de tudo pelos três e eles nem agradecem". A visão de futuro de que não conseguirá mais ter paz em sua vida quando fala "Estamos presos [...] nós podemos devolver as crianças".

Pete se vê como um pai que não está preparado para adotar as crianças quando fala "Achei que quando víssemos os nossos filhos haveria uma conexão cósmica". Sua visão de mundo é que para adotar precisa ser pessoas muito especiais, na sua fala "Pessoas que adotam crianças são muito especiais, são pessoas que não esperam o natal para fazer caridade e não fazemos 
caridade nem no natal". Sua visão de futuro é que não será capaz de cuidar das crianças, ao falar "Podemos cuidar de duas, mas não damos conta de três crianças", "Cometemos um erro e a nossa vida vai virar um inferno".

Juan e Lita por serem crianças tem uma visão diferente dos demais, conseguem se vê como filhos do casal criando um vínculo mais rápido que a Lizzie que é pré-adolescente, a visão de mundo das crianças menores é terem sua infância resgatada e a visão de futuro é a esperança de encontrarem um lar em que pudessem ser amados.

\section{Análise de conteúdo}

Usou-se da técnica utilizada por Skinner da análise do comportamento para verificar que um evento pode modificar o comportamento em um ambiente trazendo uma consequência. "Uma análise funcional nada mais é, pois, do que uma 'explicação' de um evento pela descrição de suas relações com outros eventos” (Matos, 1999, p. 13).

O antecedente é caracterizado por um evento que ocorreu no passado, o comportamento é a resposta do indivíduo para aquele evento e a consequência é o resultado do evento (Moreira, Medeiros, 2008). De acordo com a técnica de Skinner foi feita a análise funcional dos personagens principais demonstrado no Quadros 1,2 e 3 abaixo.

Quadro 1: Análise funcional do comportamento dos pais adotivos antes da adoção.

\begin{tabular}{|c|c|c|}
\hline ANTECEDENTE & COMPORTAMENTO & CONSEQUÊNCIA \\
\hline $\begin{array}{c}\text { O cunhado diz que o casal Ellie e } \\
\text { Pete nunca terão filhos. }\end{array}$ & $\begin{array}{c}\text { Ellie começa a pensar na } \\
\text { possibilidade em ter filhos } \\
\text { pesquisando em sites de adoção. }\end{array}$ & $\begin{array}{c}\text { Vai para uma palestra e faz o curso } \\
\text { de adoção. }\end{array}$ \\
\hline $\begin{array}{c}\text { O casal Pete e Ellie vão para a feira } \\
\text { de adoção conhecer } \\
\text { crianças/adolescentes abrigados. }\end{array}$ & $\begin{array}{c}\text { Uma adolescente chamada Lizzie os } \\
\text { aborda e fala com eles }\end{array}$ & $\begin{array}{c}\text { A menina passa uma boa impressão } \\
\text { neles e decidem adota-la. }\end{array}$ \\
\hline $\begin{array}{c}\text { Ellie e Pete visitam os irmãos } \\
\text { menores de Lizzie que também estão } \\
\text { para adoção. }\end{array}$ & $\begin{array}{c}\text { As crianças apresentam alguns } \\
\text { comportamentos difíceis de lidar. }\end{array}$ & $\begin{array}{c}\text { Repensam sobre adotar as crianças e } \\
\text { pensam em desistir da adoção. }\end{array}$ \\
\hline $\begin{array}{c}\text { Comunicam à família sobre a } \\
\text { desistência de adotar as crianças. }\end{array}$ & $\begin{array}{c}\text { A família reage demonstrando } \\
\text { estarem aliviados por desistirem da } \\
\text { adoção pois estavam com medo das } \\
\text { crianças se tornarem viciadas ou } \\
\text { criminosas. }\end{array}$ & $\begin{array}{c}\text { Ellie volta atrás na decisão após a } \\
\text { família se mostrar preconceituosa e } \\
\text { decide continuar com o processo de } \\
\text { adoção para provar que estão } \\
\text { errados. }\end{array}$ \\
\hline
\end{tabular}

Fonte: Autoras (2021).

É importante observar que os acontecimentos anteriores influenciaram os personagens a uma tomada de decisão, causando uma reação no comportamento e resultando em uma consequência. As consequências descritas no Quadro 1 fazem relação com o que acontece na vida real.

Os interessados em adotar terão que passar por uma série de requisitos avaliativos tanto por avaliação social como psicológica, além de um curso de preparação para que seja comprovado que estão aptos a adotar uma criança ou adolescente. E tudo isso pode levar um tempo considerável de espera para os pretendentes, porém esse tempo é essencial para que seja feito uma avaliação e preparação minuciosa dos futuros pais adotivos (Valério \& Lyra, 2016).

É comum os pretendentes à adoção idealizarem a criança que irão adotar, e como ela será tanto na aparência como também no aspecto comportamental, se é uma criança mais quieta, obediente, inteligente, educada, quando na realidade a criança pode ser mais agressiva, não saber ter limites, com pouca instrução de estudo e muitas vezes esses pais adotivos podem sentir uma incompatibilidade e frustração (Bragança \& Pereira Junior, 2015). 
É importante o apoio da família, pois muitas vezes alguns familiares vem carregados de pré-julgamentos sobre a adoção por não terem conhecimento, sendo influenciados por notícias que podem aparecer na mídia de casos de crianças adotadas que não deram certo, por acharem que o pai que é viciado em drogas vai passar o gene "ruim" para a criança, e isso geralmente é um preconceito enraizado culturalmente (Weber, 2003).

Quadro 2: Análise funcional do comportamento no período de convivência.

\begin{tabular}{|c|c|c|}
\hline ANTECEDENTE & COMPORTAMENTO & CONSEQUÊNCIA \\
\hline $\begin{array}{l}\text { Ellie sugere uma divisão de } \\
\text { tarefas em casa }\end{array}$ & Lizzie não gosta e se chateia & $\begin{array}{l}\text { Ellie e Pete usam uma técnica de } \\
\text { relaxamento que aprenderam no grupo de } \\
\text { apoio para pais adotivos. }\end{array}$ \\
\hline $\begin{array}{l}\text { Lita reclama que não tem batata } \\
\text { frita no jantar e se recusa a comer. }\end{array}$ & $\begin{array}{l}\text { Lizzie tenta ajudar brigando } \\
\text { para que Lita coma, mas Ellie diz } \\
\text { para deixar que ela resolva }\end{array}$ & $\begin{array}{l}\text { Lita tem uma fúria de raiva, grita na } \\
\text { mesa e joga comida em Ellie, gerando um } \\
\text { verdadeiro caos. }\end{array}$ \\
\hline $\begin{array}{l}\text { No supermercado, Lita grita } \\
\text { querendo que compre uma Barbie } \\
\text { para ela. }\end{array}$ & Ellie se recusa a comprar & $\begin{array}{l}\text { Se torna uma verdadeira briga, e } \\
\text { Lizzie acaba cedendo e comprando a } \\
\text { Barbie para a irmã. }\end{array}$ \\
\hline $\begin{array}{l}\text { Lizzie está na mesa mexendo } \\
\text { no celular. }\end{array}$ & $\begin{array}{c}\text { Ellie pede para que ela não } \\
\text { mexa no celular quando estiver na } \\
\text { mesa. }\end{array}$ & $\begin{array}{l}\text { Lizzie a desafia mostrando a foto da } \\
\text { mãe biológica no celular e diz que não } \\
\text { podem tirar objetos pessoais dela. }\end{array}$ \\
\hline $\begin{array}{l}\text { Mãe de Pete compra ingressos } \\
\text { para as crianças irem ao parque de } \\
\text { diversões. }\end{array}$ & $\begin{array}{l}\text { Lizzie faz uma expressão facial } \\
\text { para que Ellie a deixe ir. }\end{array}$ & $\begin{array}{l}\text { Ellie cede e os leva para o parque de } \\
\text { diversões. }\end{array}$ \\
\hline $\begin{array}{l}\text { Lizzie sai com as amigas depois } \\
\text { do parque e não dá notícias, acaba } \\
\text { voltando mais tarde que o } \\
\text { combinado }\end{array}$ & $\begin{array}{l}\text { Pete, Ellie e a vó Sandy brigam } \\
\text { com ela e Pete a coloca de castigo }\end{array}$ & $\begin{array}{l}\text { Lizzie mostra um presente que } \\
\text { comprou para sua avó Sandy, que acaba } \\
\text { não brigando mais com ela. }\end{array}$ \\
\hline $\begin{array}{l}\text { Ellie e Pete usam uma técnica } \\
\text { para acalmar Lizzie }\end{array}$ & Lizzie já conhecia a técnica & $\begin{array}{l}\text { A técnica não funciona e Lizzie fica } \\
\text { com raiva por usarem a técnica com ela }\end{array}$ \\
\hline $\begin{array}{l}\text { Lizzie está com o cabelo } \\
\text { embaraçado }\end{array}$ & Ellie penteia o cabelo de Lizzie & Lizzie chora \\
\hline $\begin{array}{l}\text { Ellie dá a escova de cabelo de } \\
\text { presente para Lizzie }\end{array}$ & $\begin{array}{l}\text { Lizzie penteia o cabelo e } \\
\text { lembra da mãe biológica }\end{array}$ & $\begin{array}{l}\text { Lizzie joga a escova de pentear no } \\
\text { vaso sanitário }\end{array}$ \\
\hline
\end{tabular}

Fonte: Autoras (2021).

No Quadro 2 retrata como é o convívio na fase de adaptação e os desafios a serem enfrentados, demonstrando como os comportamentos anteriores afetam os comportamentos futuros trazendo-lhes consequências positivas ou negativas.

É importante participar de grupos de apoio à adoção onde os futuros pais adotivos irão trocar experiências vividas que passaram pela mesma situação, o psicólogo pode coordenar esse grupo e assim contribuindo para a preparação desses pretendentes (Sequeira \& Stella, 2014).

Crianças maiores é mais difícil na adaptação familiar pois quanto mais idade a criança tiver, maior é a chance dela possuir experiências traumáticas, ela vem com falta de afeto e cuidado e muitas vezes fará provocações com os pais adotivos para saber se é amada naquela família, sendo algo involuntário (Souza, 2012).

Portanto é de extrema importância que os pretendentes à adoção tenham um preparo antes mesmo de adotar uma criança/adolescente, pois dificuldades irão surgir e ao estar preparados esses futuros pais saberão lidar melhor com os desafios encontrados e assim evitará uma possível desistência no processo ou até mesmo a devolução da criança/adolescente após a adoção (Pauliv, 2020). 
Quadro 3: Análise funcional do comportamento de Lizzie.

\begin{tabular}{|c|c|c|}
\hline ANTECEDENTE & COMPORTAMENTO & CONSEQUÊNCIA \\
\hline $\begin{array}{l}\text { Lizzie está com raiva dos pais } \\
\text { adotivos. }\end{array}$ & $\begin{array}{c}\text { Pete a leva para extravasar a raiva } \\
\text { quebrando objetos em uma casa de } \\
\text { demolição. }\end{array}$ & $\begin{array}{c}\text { A relação pai e filha é melhorada e o } \\
\text { vínculo é fortalecido. }\end{array}$ \\
\hline $\begin{array}{l}\text { Lizzie pergunta porque quiseram } \\
\text { adota-los. }\end{array}$ & O casal não tem resposta. & Lizzie não se sente amada. \\
\hline $\begin{array}{l}\text { A mãe biológica de Lizzie não vai } \\
\text { busca-la. }\end{array}$ & $\begin{array}{l}\text { Lizzie fala para Ellie e Pete que irá } \\
\text { voltar a morar no abrigo. }\end{array}$ & $\begin{array}{l}\text { Ellie e Pete não aceitam e pedem que } \\
\text { Lizzie continue morando com eles. }\end{array}$ \\
\hline $\begin{array}{c}\text { Ellie entrega uma carta para Lizzie } \\
\text { lê. }\end{array}$ & $\begin{array}{l}\text { Lizzie lê a carta onde fala o motivo } \\
\text { do porquê eles quiseram adotar. }\end{array}$ & $\begin{array}{c}\text { Lizzie percebe que é verdadeiramente } \\
\text { amada pelos seus pais adotivos. }\end{array}$ \\
\hline
\end{tabular}

Fonte: Autoras (2021).

No Quadro 3 foi descrito alguns dos comportamentos de Lizzie, onde é possível observar que ela não acreditava em ser amada por aquela família, havendo um sentimento de desconfiança e medo.

Geralmente o adolescente desiste da adoção por alguns fatores, podendo ser por conta do trauma que teve na família biológica em que teme passar pelo mesmo novamente e pode acontecer da criança/adolescente ter esperança de retornar para os pais biológicos um dia, pois já tem um afeto pelos pais que não se permite criar com nenhuma outra família (Souza, 2012).

\section{Análise da imagem e do som}

O som é importante para um filme pois ele irá transmitir emoções como o medo, tristeza, alegria fazendo com que o espectador se sinta como parte do filme, o ruído ou som geralmente é apresentado antes de surgir a imagem, com a intenção de causar um sentimento afetivo por parte dos espectadores (Carreiro, 2011).

Foi feito um compilado de cenas para cada momento no filme que tocou músicas para cada tipo de emoção, onde foi feito uso de materiais sonoros para trazer a emoção necessária para a cena.

\section{$\underline{\text { Medo }}$}

Em 1:00':06" de filme a câmera foca em Lizzie que grita para Juan soltar o pinador que estava em suas mãos, logo em seguida entra um som de fundo de suspense, seguido de gritos e ruídos altos, que é o momento em que Juan sem querer enfia um prego no pé. Fazendo com quem estar assistindo sentir apreensão na cena.

No minuto 1:16':31" Lizzie pede para se encontrar com a mãe biológica, toca um som de fundo melancólico que demonstra o medo que estabeleceu em Ellie e Pete de serem trocados pela mãe biológica.

\section{$\underline{\text { Tristeza }}$}

Em 1:03':49' toca uma música lenta, onde é o momento que Ellie está penteando o cabelo da adolescente Lizzie que começa a chorar.

No minuto 1:39':40" toca uma música onde eles estão chorando pois terão que se mudar para a casa da mãe biológica e não irão mais conviver com a Ellie e Pete.

No minuto 1:42':59' Lizzie recebe a notícia que sua mãe biológica não vai busca-los e que voltou a usar drogas, sendo inviável ela ficar com a guarda deles, fazendo com que Lizzie chore e fuja. 
$\underline{\text { Alegria }}$

Em 1:02':39" é colocado um som onde a adolescente Lizzie diz para a assistente social que os pais adotivos não tiveram culpa em deixar o Juan se ferir, ela assume a culpa por querer continuar morando com Ellie e Pete, significando que ela gosta de morar com eles.

No minuto 1:10':12" toca uma música de alegria onde Pete leva Lizzie para extravasar a raiva quebrando objetos de uma casa que está para demolição, fazendo com que Lizzie se sinta melhor depois da discussão que teve com a mãe adotiva Ellie.

No minuto 1:12':14" toca uma música animada, passando alguns momentos que eles passaram juntos como família e começam a criar um vínculo, conhecendo um ao outro.

No minuto 1:15':00" toca uma música lenta onde é a primeira vez que Juan chama Ellie de mãe e ela se emociona demonstrando que o vínculo está sendo estabelecido entre eles.

No minuto 1:51':10" toca uma música lenta no dia da adoção, onde eles se emocionam pois é a cerimônia para que as crianças sejam oficialmente adotadas por Ellie e Pete, fazendo com que o espectador tenha um sentimento de alívio.

\section{Considerações Finais}

Considerando o estudo feito para a identificação dos aspectos comportamentais no processo de adoção de adolescentes e crianças esse trabalho analisou o filme de três formas, a primeira pela vertente cognitiva na análise textual descrevendo alguns pensamentos negativos e consequentemente inseguranças que cada um dos personagens carregava consigo e que era um fator que estava impedindo uma boa relação familiar. Na segunda, a análise de conteúdo foi descrita com os comportamentos de cada personagem onde foi possível relacionar esses comportamentos com cada etapa do processo de adoção. Na terceira, a análise da imagem e do som ressaltou a importância da utilização de efeitos sonoros em um filme, onde uma música é capaz de envolver o espectador na cena gerando-o uma emoção.

Concluiu-se que a criança maior tem mais resistência para ir para uma nova família e desapegar da sua família biológica pois geralmente ela não acredita que poderá receber afeto em uma nova família que não a conhece e que não tem seu mesmo sangue e acaba tendo comportamentos difíceis de lidar e por isso acontece de alguns pais acolhedores desistirem de uma possível adoção.

Esse trabalho alcançou aos objetivos propostos e busca provocar mais pesquisas acerca do assunto, delimitando a importância de se pensar e falar sobre quando o abrigado não aceita a adoção e o que está por trás dessa decisão. Tendo um impacto para a comunidade científica que estará contribuindo com um olhar para as crianças/adolescentes que vivem na instituição sem um convívio familiar e para a sociedade que muitas vezes possui estigmas acerca do processo de adoção onde acaba criando mitos em torno de pensamentos do senso comum.

Além disso, vale ressaltar a importância de mais pesquisas que englobem análises de filmes nessa temática pois constata-se poucos estudos publicados utilizando esse tipo de metodologia. Destaca-se também a necessidade de pesquisas de campo com grupos focais que busquem uma melhor compreensão das dificuldades de criação de vínculos do público infantil e adolescente no processo de adoção.

\section{Referências}

Amora, A. S. (2009). Minidicionário Soares Amora da língua portuguesa. (19. ed.). São Paulo: Saraiva.

Bragança, R. R. \& Pereira Junior, A. A. (2015). Crianças institucionalizadas: a demora na adoção. Rev. Uningá Review, 23(3), 89-97. https://www.mastereditora.com.br/periodico/20150902_105856.pdf

Brasil. (2009)._Lei federal no 12.010, de 3 de agosto de 2009. Brasília, DF. https://www.planalto.gov.br/ccivil_03/_ato2007-2010/2009/lei/112010.htm 
Research, Society and Development, v. 10, n. 16, e161101623404, 2021

(CC BY 4.0) | ISSN 2525-3409 | DOI: http://dx.doi.org/10.33448/rsd-v10i16.23404

Carreiro, R. (2011). Sobre o som no cinema de horror: padrões recorrentes de estilo. Rev. Ciberlegenda, 1(24), 43-53. https://www.academia.edu/4893829/Sobre_o_som_no_cinema_de_horror_padr\%C3\%B5es_recorrentes_de_estilo_Revista_Ciberlegenda_. https://doi.org/10.22409/C-LEGENDA.V1I24.26201

Catania, A. C. (1999). Aprendizagem: comportamento, linguagem e cognição. (4. ed.). Porto Alegre: Artmed.

Goes, A. E. D. (2014). Criança não é brinquedo! A devolução de crianças e adolescentes em processos adotivos. Portal (SYN)THESIS. https://www.epublicacoes.uerj.br/index.php/synthesis/article/view/17350. doi: https://doi.org/10.12957/synthesis.2014.17350

Goldenberg, M. (2004). A arte de pesquisar: Como fazer pesquisa qualitativa em Ciências Sociais. (8. ed.). Rio de Janeiro: Editora Record.

Gonçalves, C. R. (2012). Direito civil brasileiro. (10. ed.). São Paulo: Saraiva.

Knapp, P. \& Beck, A. T. (2008). Fundamentos, modelos conceituais, aplicações e pesquisa da terapia cognitiva. Rev Bras. Psiquiatr., 30(supl. 2), 54-64. https://www.scielo.br/j/rbp/a/HLpWbYk4bJHY39sfJfRJwtn/?format=pdf\&lang=pt

Matos, M. A. (1999). Análise funcional do comportamento. Rev. Estudos de Psicologia, 16(3), 8-18. https://www.scielo.br/j/estpsi/a/wHqz3qV6gSPKfdL4f8CGRYg/?format=pdf\&lang=pt

Moreira, M. B. \& Medeiros, C. A. (2007). Princípios básicos de análise do comportamento. Porto Alegre: Artmed.

Paiva, L. D. (2004). Adoção: significados e possibilidades. São Paulo: Casa do psicólogo livraria e editora ltda.

Pauliv, R. (2020). A Importância da Preparação Continuada dos Pretendentes à Adoção. Associação Nacional dos Grupos de Apoio à Adoção. https://www.angaad.org.br/portal/importancia-da-preparacao-continuada-dospretendentes-a-adocao/

Penafria. M. (2009). Análise de filmes - conceitos e metodologias. VI Congresso SOPCOM, Lisboa. http://www.bocc.ubi.pt/pag/bocc-penafria-analise.pdf

Sampaio, D. S., Magalhães, A. S. \& Féres Carneiro, T. (2018). Pedras no Caminho da Adoção Tardia: Desafios para o Vínculo Parento-Filial na Percepção dos Pais. Rev. Temas em Psicologia, 26(1), 311-324. https://www.scielo.br/j/tpsy/a/Cx4bFKrqtTrPzL3vHsbCZmD/?lang=pt\&format=pdf. doi: http://dx.doi.org/10.9788/TP2018.1-12Pt

Sequeira, V. C. \& Stella, C. (2014). Preparação para a adoção: grupo de apoio para candidatos. Rev. Psicologia: Teoria e Prática, 16(1), 69-78. http://pepsic.bvsalud.org/pdf/ptp/v16n1/06.pdf. doi: http://dx.doi.org/10.15348/1980-6906/psicologia.v16n1p69-78

Souza, H. P. (2012). Adoção tardia: Devolução ou desistência de um filho? A necessária preparação para adoção. Curitiba: Juruá.

Valério, T. A. M. \& Lyra, M. C. D. P. (2016). Significados ambivalentes no processo de adoção: um estudo de caso. Rev. Psicologia em Estudo, 21(2), 337348. https://www.redalyc.org/pdf/2871/287147424015.pdf

Vergara, S. C. (2000). Projetos e relatórios de pesquisa em administração. São Paulo: Atlas.

Weber, L. N. D. (2003). Aspectos Psicológicos da Adoção. Curitiba: Juruá. 